\title{
E-Commerce Trend in Developing Countries: A Case Study of Tanzania
}

\author{
Kenneth Longo Mlelwa \\ PhD Cand., ITDSM \\ School of CoCSE, NM-AIST \\ Arusha, Tanzania
}

\author{
Bukaza Chachage, PhD \\ Lecturer, School of BuSH \\ NM-AIST \\ Arusha, Tanzania
}

\author{
Yonah O. Zaipuna,PhD \\ Senior Lecturer \\ School of CoCSE, NM-AIST \\ Arusha, Tanzania
}

\begin{abstract}
As the World Wide Web (www) has grown so is the number of eCommerce merchants has also grown. As there are some very well-known and high profile eCommerce success stories so are many, many failures. The Internet has become an important channel for business success, and as such it is becoming the channel for communications and transactions. This has led to growth in eCommerce; and as this has grown so has the concerns about security. Often said security and trust are main reasons for consumers not purchasing from internet. Unlike traditional commerce absence of physical clues and physical interaction in the online environment make it more difficulties to establish trust with the consumers. Hence it more important for online venders to learn how to manage customer's trust in eCommerce. Although creating a customer's trust on online is a challenge for most eCommerce companies. This paper presents the results of the initial work of the study on A Novel framework for Assuring Secure eCommerce Transactions in developing countries with Tanzania as a case study.
\end{abstract}

\section{Keywords}

eCommerce, Trend, eCommerce Trend, Tanzanian eCommerce Trend.

\section{INTRODUCTION}

Tanzania has 7,590,794 internet users out of estimated population of 44,928,923 as of June 2014 with an internet penetration rate of $15.3 \%$ [1]. With the introduction of the first fiber optic international submarine cables in 2009 and 2010 is set to revolutionize the internet activities of which up to that point was completely rely on expensive satellite connections [2]. Due to that the number of ISP in Tanzania has risen to 24 from 13 by 2002 [3].

Intensively usage of Internet services is a hub for sustainability of both socio and economic developments as it has enabled implementation of e-government, e-learning, ehealth, e-commerce to mention a few [4].

To better understand Electronic commerce (commonly known as E-commerce or eCommerce), one should distinguish between e-commerce and electronic business (e-business), Ecommerce means electronic buying and selling on the Internet. E-business is any electronic transaction (e.g., information exchange), which subsumes e-commerce. Ebusiness encompasses all the activities that a firm performs for selling and buying services and products using computers and communications technologies as such e-business includes a host of related activities, such as on-line shopping sales force automation supply shopping, automation, chain management, electronic payment systems, web advertising and order management [5].

Again, e-commerce is a subset of e-business. However, sometimes the two are used interchangeably. Consequently,
E-business, a major contributor to the popularity of global information technologies, is a system that includes not only those business that center on buying and selling of goods and services to generate revenue, but also those transactions that support revenue generation.

Holistically, e-commerce means using technological advances to promote everything involving the exchange of business information among computers and humans or traders and customers [6] [7].

The concept of "transactional" e-commerce is further divided into four categories [8]. These categories are business to business (B2B) [9]; business to consumer (B2C); consumer to business (C2B); and consumer to consumer (C2C) [10] [11].

\section{LITERATURE REVIEW}

Globally eCommerce is a growing sector which has so far yielded positive results. Since early 1990's there was almost no any activity online as the Internet was a new concept. In 1999, 300 million users were online and about 75 million of them purchased goods and services via online worth $\$ 110$ billion. This increase rapidly and by 2013 the amount in online transactions had increase to $\$ 1.25$ trillion [12].

In 2010, the United Kingdom had the highest e-commerce market in the world when measured by the amount spent per capita [13]. The Czech Republic is the European country where ecommerce has the highest contribution to the enterprises' total revenue. Almost a quarter $(24 \%)$ of the country's total turnover is generated by eCommerce channel [14].

Other emerging economies, China's e-commerce presence continues to grow every year. About 384 million internet users, China's online sales rose to $\$ 36.6$ billion in 2009 and this is due to the huge growth has been the improved trust level for shoppers. The Chinese merchants have been able to help online shoppers feel more comfortable [15]. China's cross-border e-commerce is also growing with a good pace. Ecommerce transactions between China and other countries increased 32\% to 2.3 trillion yuan ( $\$ 375.8$ billion) in 2012 and accounted for $9.6 \%$ of China's total international trade [16] in 2013, Alibaba had an e-commerce market share of $80 \%$ in China [17].

The increase Internet penetration, the spread of mobile technology and improvement of payment and delivery infrastructure are parameters that can boost eCommerce in Africa. The increase of middle class seeks more convenient shopping and better quality; attract both local and international Internet merchants to operate. [18]

In Africa, 720 million people have access to phones and 167 million have Internet access [19]. With internet penetration rapidly spreading across the East African region, this represents huge potential which has hitherto been untapped. In 
Kenya, there are about 30 million mobile phone subscribers and Internet penetration is also currently at $49.7 \%$, with mobile data subscriptions making up most of it. Despite most people accessing Internet via mobile phones, fixed fiber subscriptions have also grown by $86.8 \%$ from FY 2011/2012 to FY 2012/2013 [19].

Despite positive trends in both mobile and Internet penetration, growth across countries varies and in some cases drastically. Mobile penetration in Tanzania for example, is at $60 \%$ and internet penetration at 12\%; much lower than Kenya. In Kenyan however, urban areas mobile and internet use is much higher than rural or even national numbers. Mobile phone penetration in the country is at $72 \%$. In urban areas, $72 \%$ are online, $95 \%$ have internet capable mobile phones and $31 \%$ have smart phones [19]

E-commerce is poised to dominate East African retail markets over the next five years, [20] While market watchers may not be quite as optimistic in their forecasts, no one disputes that ecommerce on the continent is starting to take root [21].

\section{METHODOLOGY}

\subsection{Design of the study}

Since the study is aimed at examining eCommerce trends in developing countries: a case of Tanzania. The methodology adopted in the study is exploratory case study. In social sciences and life sciences, a case study is a research method involving an up-close, in-depth, and detailed examination of a subject of study (the case), as well as its related contextual conditions. Although no single definition of the case study exists, case-study research has long had a prominent place in many disciplines and professions [22] [23].

\subsection{Population}

The targeted population for this study was defined as the totality of all stakeholders involved in eCommerce activities (mostly consumers) and aware of the opportunities that eCommerce has in developing countries. The population of interest is usually defined by the purpose of the research and the research question itself [24].

\subsection{Sampling technique}

Sampling is a process during which decisions are made on what and how to sample. A non-probability purposeful sampling will be used to obtain a sample of informants that will help obtain rich information based on their experiences. The study area was divided into various parts. Then, proportionate split of respondent was done for each part. Lastly, random sampling of participants was done from a defined population of interest [25].

\subsection{Data collection method and procedure}

The semi-structured interview technique [26] was carried out with various customers. The semi structured interview technique based on a pre-prepared topic was used to guide data collection. In this study, a questionnaire was used as a research tool. It was prepared and submitted to various respondents. Before collecting the data, a questionnaire was fully examined and pre-tested by the researchers. Then, it was cross-checked for apparent mistakes and unclear signals, and numbered for easy computerization and identification of each respondent.

\subsection{Data analysis}

All filled responses were edited to ensure accuracy and consistency in capturing information from the field. Using statistical Package for Social Sciences Software (SPSS), the captured data was analyzed to produce frequency graphs and histograms. From frequency graphs and histograms interpretations have been done according to the research questions and objectives. Findings from in-depth interviews and focus group discussions regarding a customers' experience on e-commerce activities, challenges, and perception was complemented by questionnaire using a quantitative approach. Both qualitative and quantitative data was used so as to help the researcher to realize and appreciate the experience of eCommerce trend in developing countries.

\section{RESULTS AND DISCUSSION}

\subsection{1 eCommerce users Demographics}

the researcher analyzed 213 responses collected through an online survey. Most respondents were of the age below 41 years (only $6 \%$ was above 41 years) and mainly male (62\%) (Figure $1 \& 2$ ). One of the limitations faced while using the data collection tool was the representation of females being drastically low. Also found that only $7 \%$ of respondents had education at level of secondary education and below. 67\% (Figure 4) responded as having a positive attitude towards purchasing goods and services over internet. Only $15 \%$ were of negative attitude and the rest said they have no opinion on that.

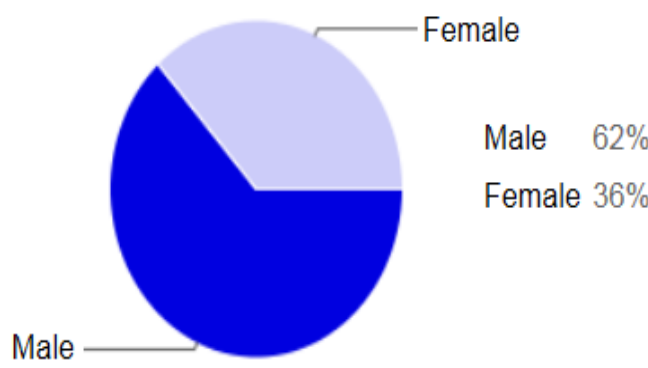

Fig 1: Represents Gender distribution among respondents

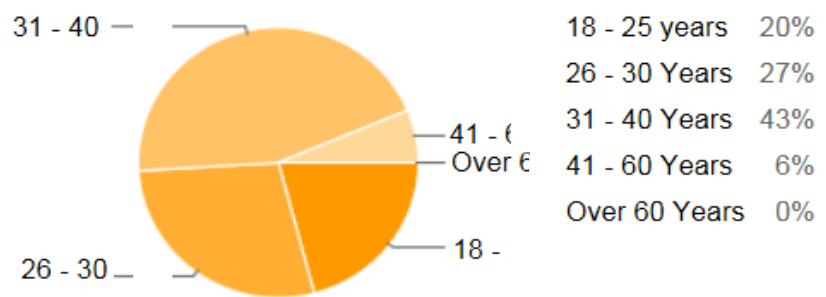

Fig 2: Represents the age distribution among respondents

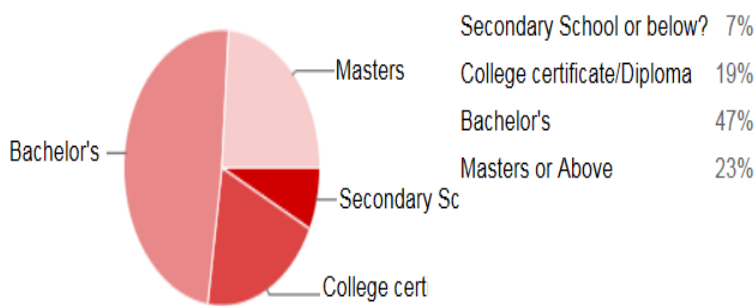

Fig 3: Represents the Education distribution. 


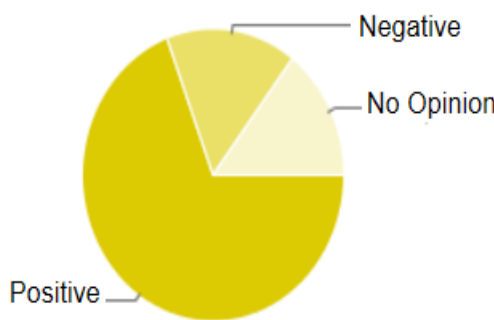

Positive $\quad 67 \%$

Negative $15 \%$

No Opinion $14 \%$

Fig 4: Represents an attitude towards purchasing goods/services over internet

\subsubsection{Usage and Barriers for online shopping}

In terms of usage of internet for shopping 100 respondents which is $47 \%$ they said they have never used an internet for shopping, and this could be coursed by either their worries about their safety of payment and Low trust level of online store. The following figures (Figure number $5 \& 6$ ) depict this.

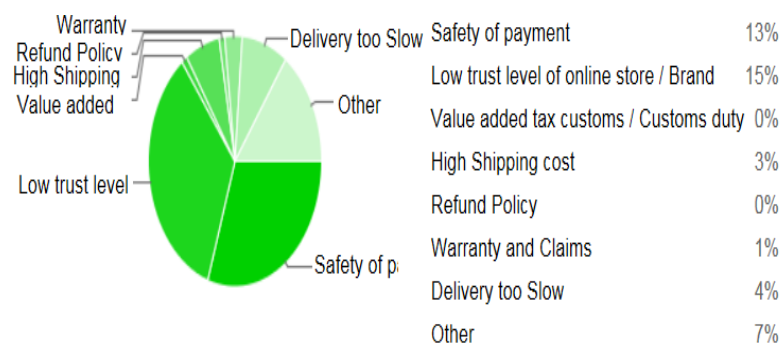

Fig 5: Showing the barriers for online shopping

\subsection{3 eCommerce trend}

It has been noted that; for the past three year number of online shoppers has been increased each year (figure 6), which means more awareness to eCommerce with the introduction of smart phones has catalyst an online shopping activities, and electronics goods such as Mobile phone and laptop (59\%), Clothes (40), Music/Software (28\%) and Books (26) are among the major product which customers are normally bout online however still there is significant number of other commodities $(29 \%)$ such as buying electricity online and payment of air ticket is among the major activities for online shoppers.

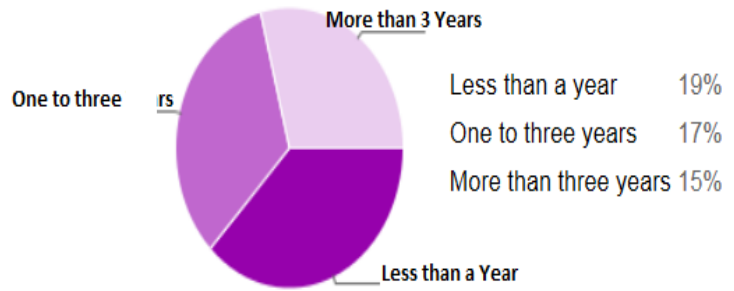

Fig 6: Depict as how long have they been shopping online

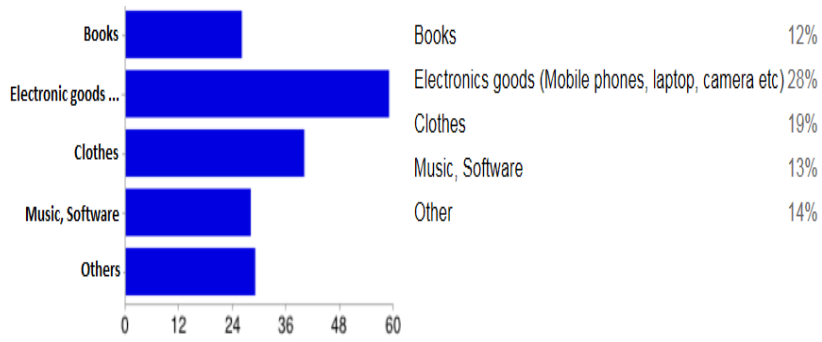

Fig 7: Showing popular online shopped product
The main reasons which force the above significant customers to shop online according to this study including Convenient and Time saving (64\%), Price (47) and Brand conscious (26\%). It has been found that 28\% (Figure 9) of those who are normal shopping online they have to go to retail store before making their final purchase. Again except $8 \%$ the rest responded that they do visit more than one online store before they make their mind on actual purchase figure 10 depict this

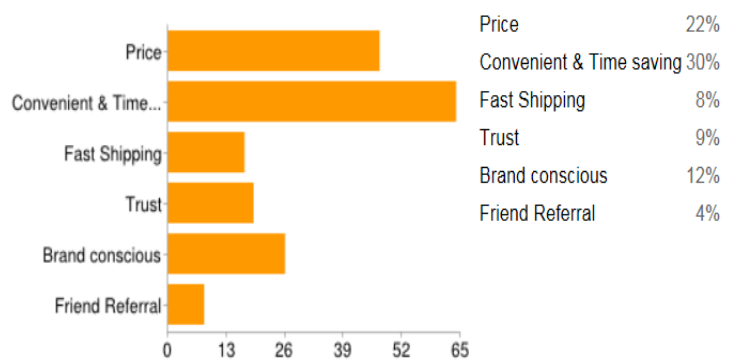

Fig 8: Represents the main reasons for online shopping

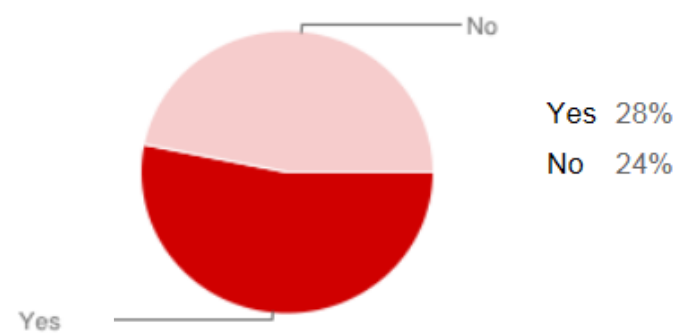

Fig 9: Showing if the online customer visiting traditional store before purchasing online.

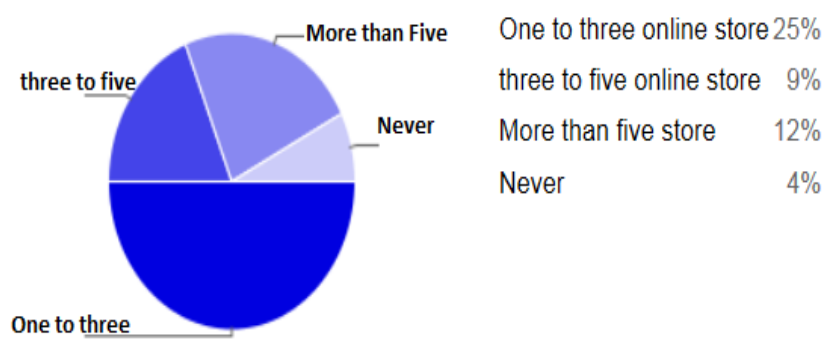

Fig 10: Showing if the online customer visiting other online store before purchasing online.

Results from various respondents found that; an online advertisement play a vital role on recruiting the online purchaser as from this study found that about $24 \%$ of respondents have been attracted first by the advertisement before they purchase online and $20 \%$ of respondents they have been referred by their either friends or family of a certain product before they makeup to purchase. Figure 10 depict this.

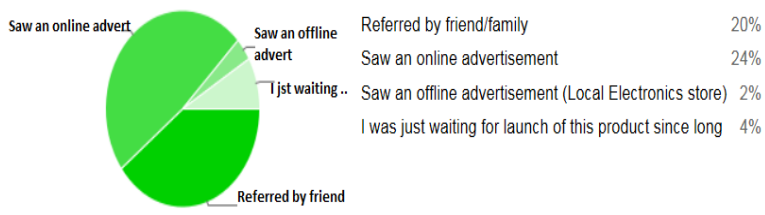

Fig 11: Represent where they got Ideas before buying product online. 


\subsubsection{Security and Privacy}

One of the critical success factors of e-commerce is security and privacy. Without the assurance of it, eCommerce may not work normally. And it is a complexity issue, because ecommerce security relates to the confidence between sellers and buyers, there is wide agreement between academic researchers that security is not only a technical challenge; rather it involves managerial, organizational and human dimensions to be more effective [27] [28]. Therefore, understanding (and acting upon) the customer's perception of security is vital to successful e-commerce interactions, because even when a company uses the best technical solutions that provide full security, without the underlying perception and awareness from customers that their particular website is secure, then these technical solutions may mean nothing.

As can be seen in figure 12 below the vast majority of the respondents, $26 \%$ and $15 \%$ perceived secure and reliable payment systems to be very important.

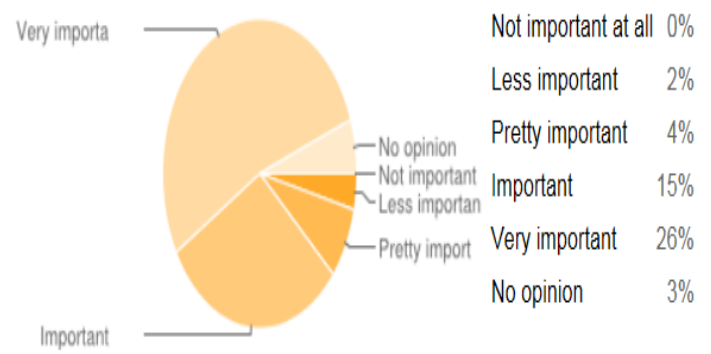

Fig 12: Showing important of Secure and Reliable payment systems

On category of information about how security work, the researcher found that $24 \%$ and $14 \%$ of respondents perceived this sub factor to be very important and important respective. This percentage shows a great majority which is almost a slight different compare on the previous factor.

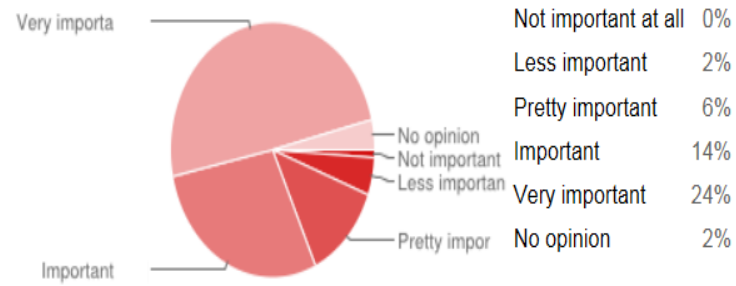

\section{Fig 13: Depict Customers information about security} issues

Again on figure 13 depict that majority of respondents thought that it is very important to have the possibility to choose payment method. Here a great majority of the responses are on the alternatives" "important" and "Very important".

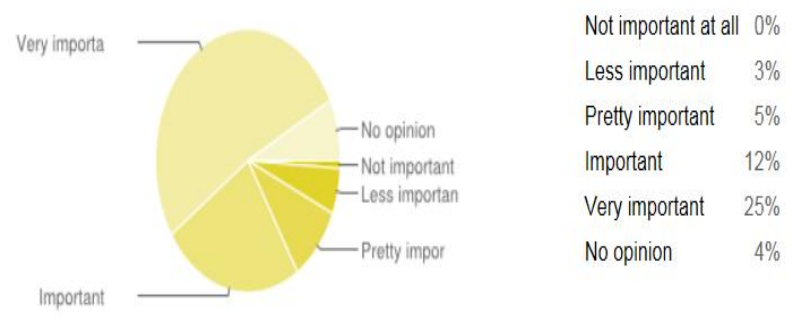

Fig 14: Showing customers' possibilities of choosing payment methods

Results from various respondents showed that; a majority of respondents thought that it is very important to know how their personal information is handled, such that their personal details won't end up in the hands of wrong guys.

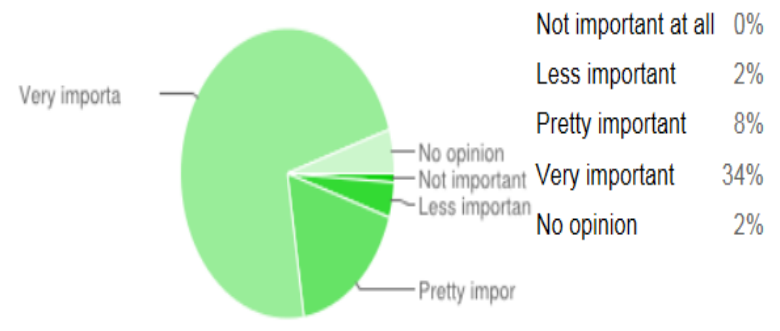

Fig 15: Depict handling your personal information that you fill when ordering is handled.

It was also found that; most of the respondents surveyed on category of policy for handling of personal information on company's web site, were $28 \%$ responded "Very important" and $11 \%$ respond "Important". So, a clearly privacy is of great importance for the respondents to feel trust.

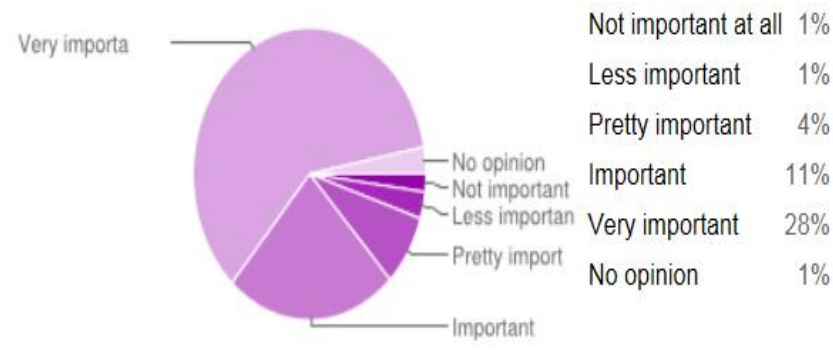

Fig 16: Depict handling your personal information on a company's website.

\subsubsection{Guarantee and Customer Services}

This part is concerned with a measure of a customer's Guarantee and Services, Previous studies [29] have found that loyal customers are crucial to eCommerce survival because the competition is just a mouse click away. Unfortunately, there are always situations where service failure occurs during service delivery. The service recovery policy is considered a key factor to influence customer satisfaction [30]. It has been noted that; the majority of respondents answered Very important and important on a category of standard terms in connection to the order form (see figure 17).

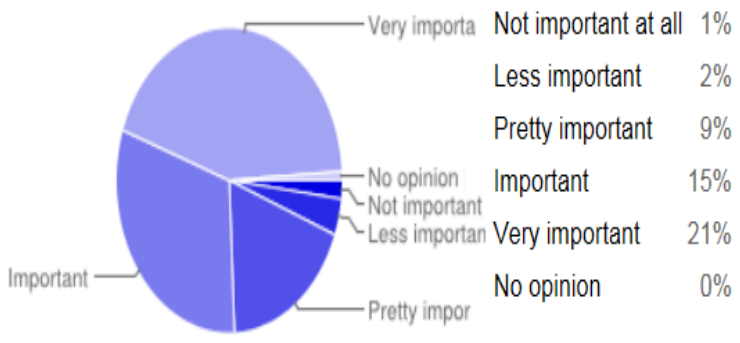

Fig 17: rating of the standard term in connection to the order form.

Again the respondents perceive the following sub-factors as equally important since their distribution of answers are almost the same. Figure 18 and 19, Depict that. Simply 
because these two sub-factors has some similarity with a traditional business and for the place where by eCommerce is still at the infant level then this can attract more customer than your competitors.

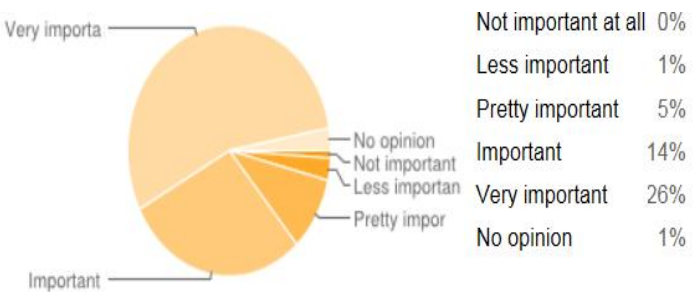

Fig 18: Confirmation on order and purchase.

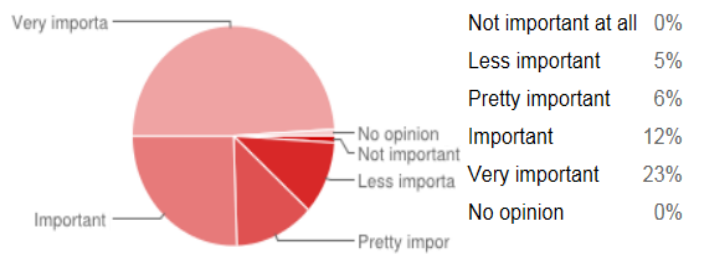

Fig 19: Possibilities of getting help online.

\subsubsection{Website and Brand}

The internet offers both growth and loyalty opportunities for brands. To this end, over the recent years, companies have accelerated the development of their websites, including richer and more interactive content. In this study it has been demonstrated that visitors satisfied with their overall website and brand experience in Figure 20 and 21 show that Brand, Reputation and recommendation of the Brand users are rate it in almost the same this two factor implies that customers are more inclined to revisit and recommend the site and in turn develop more positive attitudes toward the brand as well as higher purchase intent.

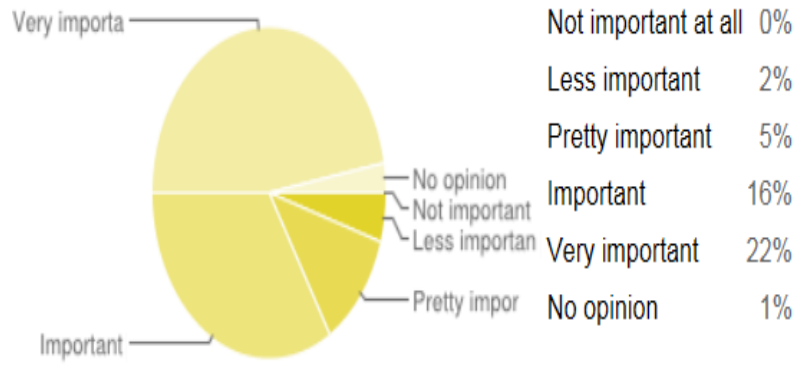

Fig 20: Rating of the product brand.

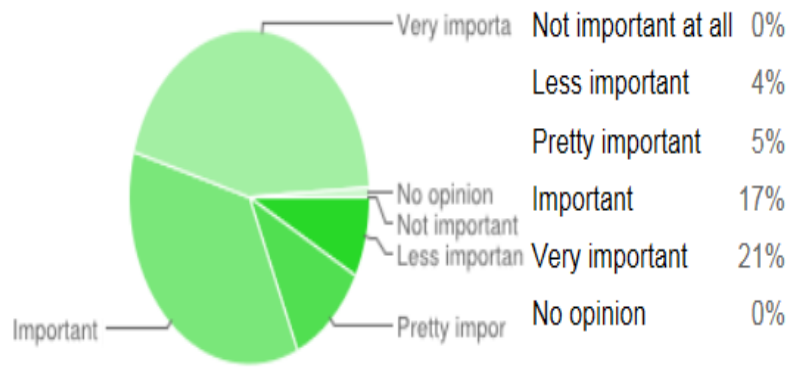

Fig 21: Reputation and Recommendation.

It was also found that: the design of the website is not much important only what matter is the functionality as on the design of the website only $16 \%$ and $13 \%$ were responded on Very important and Important respective while on functionality of the website almost $23 \%$ responded "Very important" and $12 \%$ respond as "Important".

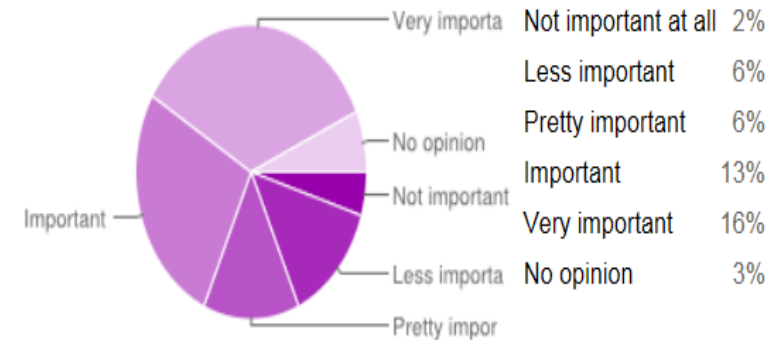

Fig 22: Rating of the design of the website.

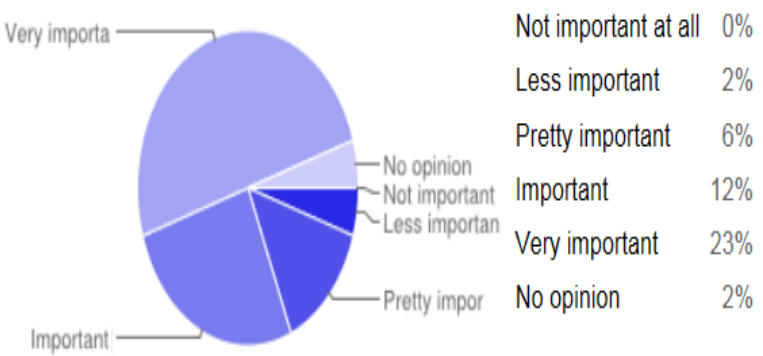

Fig 21: Rating of the functionality of the website.

\subsubsection{Control and Price}

One important way in which information technology is affecting work is by reducing the importance of distance. The Internet is a powerful means to connect buyers and sellers quickly, efficiently, and at a very low cost, regardless of whether there are just a few trading partners or thousands. Sharing product information and enabling online ordering is just the beginning. Transform online business is the adoption of dynamic pricing as an integral piece in the overall ecommerce solution is the next wave. In this study the question of "how do you rate about the convenient with using internet and the technology?" Was imposed to interviewers were by the majority responds on Very important $(21 \%)$ and $16 \%$ responded on just important thus this implies inventing new techniques of doing business online would results in attracting more customers especial in developing countries like Tanzania.

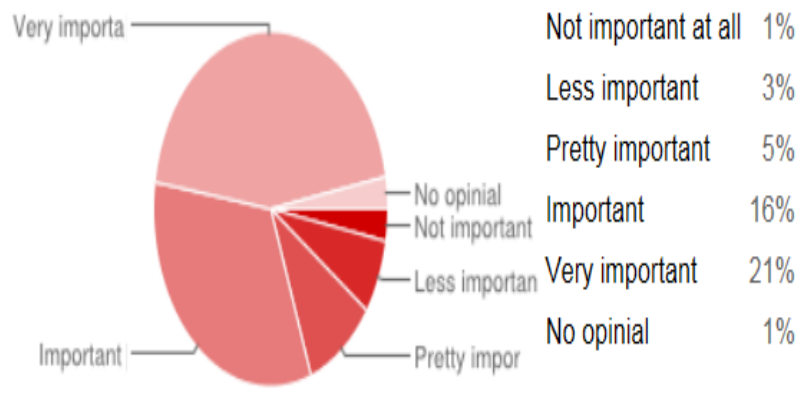

Fig 22: Convenient with using internet and the technology.

It has been found that; the majority of respondents about $27 \%$ (Figure 23) answer that the price a very important factor for online shopping. 


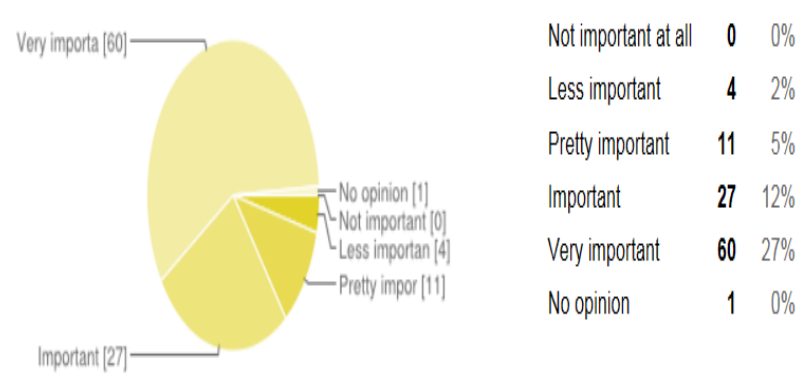

Fig 23: Important of the price of the product/Services.

\section{CONCLUSION AND RECOMMENDATIONS}

As the results of the initial work of the study on A Novel framework for Assuring Secure eCommerce Transactions in developing countries a case study of Tanzania, this paper has focused on examining the trend of eCommerce in developing countries. As e-commerce is rapidly growing in developed countries to the contrary, in developing countries especial in Tanzania it is completely different. According to this study Trade over the Internet has not been quickly adopted in this region because there are a number of challenges that have mitigated eCommerce to properly take off. These challenges which associated with eCommerce in developing countries is a great reality; this is mainly because of the environment, In the light of the above, The following are the recommendation based on this study.

- A lot of attention should be paid to infrastructural issues that will culminate in its rapid development as that is the very foundation of eCommerce. Such that the issues of epileptic internet coverage, bandwidth and appropriate technology that can help overcome the limitations of the local environment should be given a lot of priority.

- Investment in trainings and other enlightenment programs is a very vital to attitudinal changes to the public as from this study, $47 \%$ of respondents claims that they have never used this kind of services however in figure 3 above $67 \%$ of respondents they said there are attitude toward eCommerce is positive where by $15 \%$ was negative and $14 \%$ they have no opinion. This implies that there are need of publicity on it.

- The challenge of cost development and finance which makes eCommerce not to be cost effective to end users should be improved on.

- Adequate attention should be paid to risks and security, which is a major issue why consumers shy away from using eCommerce in general; figure 5 above depict that those $47 \%$ who has never used this service their main reason was mainly safety of payment and low trust.

- To ensure eCommerce success, financial and regulatory issues must be tackled. Ecommerce defined simply as electronic delivery of a product or service implies that customs and taxation regulations must be altered

Conclusively the trend of eCommerce in developing countries particularly in Tanzania is a promising though it is still at infant level, the few recommendations above can go a long way in helping to excel the trend of eCommerce in a positive manners.

\section{REFERENCES}

[1] http://www.internetworldstats.com/stats1.htm accessed on 2nd April 2015

[2] http://www.internetworldstats.com/af/tz.htm as accessed on 2nd April 2015

[3] http://www.tix.or.tz/tispa/members.html as accessed on 2nd April 2015

[4] http://www.thecitizen.co.tz/Business/Tanzania-sInternet-users-hit-9m/-/1840414/2254676/-/dgt0ps//index.html as accessed on 2nd April 2015

[5] Kenneth Mlelwa (2011) "E-Commerce Awareness and Its Impact on the Small Scale Tourism", research Report

[6] Kaetzel L.J E-commerce and IP on the Internet 1996 page 186

[7] Curie Wendy (2000). "The Global Information Society". Chichester, John Wiley \& Sons, Ltd.

[8] Evans, R. (2002). E-commerce, competitiveness and local and regional governance in Greater Manchester and Merseyside: Apreliminary assessment. Urban Studies, 39(5/6) 947+.

[9] Shelly, Gary (2011). Systems analysis and design. Boston, MA: Course Technology, Cengage Learning. p. 10. ISBN 0-538-47443-2.

[10] Garbade, Michael (2011). Differences in Venture Capital Financing of U.S., UK, German and French Information Technology Start-ups A Comparative Empirical Research of the Investment Process on the Venture Capital Firm Level. München: GRIN Verlag GmbH. p. 31. ISBN 3-640-89316-6.

[11] http://www.digitsmith.com/ecommerce-definition.html as accessed on 10th March 2015

[12] World Trade Organization. (2013). E-commerce in developing countries: Opportunities and challenges for small and medium- sized enterprises.

[13] Robinson, James (28 October 2010). "UK's internet industry worth £100bn". The Guardian (report) (London). Retrieved 21 December 2012.

[14] Eurostat (18 June 2013). "Ecommerce contribution in Europe" (infographic). Retrieved 18 March 2013.

[15] Olsen, Robert (18 January 2010). "China's migration to eCommerce". Forbes.

[16] Tong, Frank (16 September 2013). "China's cross-border e-commerce tops $\$ 375$ billion in 2012". Internet Retailer.

[17] Steven Millward (17 September 2014). "Here are all the must-see numbers on Alibaba ahead of record-breaking IPO". Tech in Asia. Retrieved 17 September 2014.

[18] yStats.com (December 2013) "Africa B2C e-commerce report 2013. Retrieved 10 March 2015

[19] Manyika, J., Cabral, A., Moodley, L., Moraje, S., Yeboah-Amankwah, S., Chui, M., \& Anthonyrajah, J. (2013). Lions go digital: The Internet's transformative potential in Africa. McKinsey \& Company.

[20] CCK. (2013). Quarterly sector statistics report fourth quarter of the financial year 2012 / 13. Communications Commission of Kenya (CCK). 
[21] http://www.pcworld.com/article/2855252/ecommercebecomes-a-force-in-african-retail-market.html as it accessed on 9th March 2015

[22] Mills, Albert J.; Gabrielle Durepos; Elden Wiebe. (Eds.). (2010). Encyclopedia of Case Study Research. Sage Publications. California. p. xxxi. ISBN 978-1-41295670-3.

[23] Robert K. Yin. Case Study Research: Design and Methods. 5th Edition. Sage Publications. California, 2014. Pages 5-6. ISBN 978-1-4522-4256-9

[24] Marczyk, R. G., Dematteo, D. and Festinger, D., Essentials of research design and methodology, John Wiley \& Sons. 2005

[25] Saunders, M., Lewis, P. and Thornhill, A. , Research Methods for Business Students, Fourth Edition, Prentice Hall Financial Times, Harlow, Pearson Education, 2007
[26] Kvale, S. (1996). InterViews: An introduction to qualitative research interviewing. Thousand Oaks, CA: Sage.

[27] F. Bjorck, "Institutional theory: a new perspective for research into IS/ IT security in organizations," Proceedings of the 37th Hawaii International Conference on System Sciences, 2004.

[28] J. Elofe and M. Elofe, "Information security management - a new Paradigm," Proceedings of SAICSIT, 2003, pp. 130-136.

[29] Semeijn, J., Van Riel, A.C., Van Birgelen, M.J. \& Streukens, S. 2005. 'E-services and offline fulfillment: How e-loyalty is created', Managing Service Quality, 15(2): 182-194.

[30] Grewal, D., Roggeveen, A.L. \& Tsiros, M. 2008. 'The effect of compensation on repurchase intentions in service recovery', Journal of Retailing, 84(4): 424-434. 